\section{DE SILENCIOS, DIATRIBAS Y APOYOS. LOS INTELECTUALES DE IZQUIERDA FRENTE A LA GUERRA DE MALVINAS}

SILENCES, DIATRIBES AND SUPPORTS.

THE INTELLECTUAL LEFT AGAINST

THE MALVINAS WAR

IGNACIO MORETTI .

Investigador con sede en la Facultad de Ciencias Sociales de la Universidad de Buenos Aires

E-mail: lic_moretti@yahoo.com.ar

\section{Resumen}

¿Cómo se posicionó la izquierda intelectual frente a la guerra de las Malvinas? ¿Qué mapas conceptuales y marcos comprensivos fundamentaron su posicionamiento? ¿La variable explicativa medular sobre sus disímiles posturas publicas frente a la guerra remite a sus trayectorias intelectuales e ideológicas diferenciales 0 a otras circunstancias? Con el objetivo de intentar delinear respuestas exploratorias y siempre tentativas para dichas preguntas, este artículo buscará explicitar, describir y analizar los posicionamientos de un variado grupo de intelectuales de izquierda que representan distintas configuraciones especiales, pertenencias ideológicas y trayectos, y que generalmente no han sido objeto privilegiado de los abordajes especializados: la revista Punto de Vista, el colectivo intelectual de la revista Testimonio Latinoamericano y Néstor Perlongher.

\section{Registro bibliográfico}

MORETTI, IGNACIO «De silencios, diatribas y apoyos. Los intelectuales de izquierda frente a la Guerra de Malvinas», en: ESTUDIOS SOCIALES, revista universitaria semestral, año XXVIII, $n^{\circ}$ 54, Santa Fe, Argentina, Universidad Nacional del Litoral, enero-junio, 2018, pp. 169-192.

\section{Abstract}

How the intellectual left was positioned in front of the Malvinas War? What conceptual maps and comprehensive frameworks supported their positioning? Does the core explanatory variable about their dissimilar public postures against the war refer to their differential intellectual and ideological trajectories or to other circumstances? This article seek to explain, describe and analyze the positions of a diverse group of leftist intellectuals that represent different special configurations, ideological belongings and paths, and which have generally not been privileged object of specialized approaches: the review Punto de Vista, intellectual group of the review Testimonio Latinoamericano and Néstor Perlongher.

\section{Descriptores - Describers}

intelectuales de izquierda / dictadura / guerra de las Malvinas

left intellectuals / dictatorship / Malvinas war

Recibido: 09 / 06/2017

Aprobado: 02 / 03 / 2018 
¿Cómo se posicionó la izquierda intelectual ${ }^{1}$ frente a la Guerra de las Malvinas, entendiéndose como uno de los actores predilectos sujetos de la represión, el exilio, la desaparición y persecución de la última dictadura cívico-militar? ¿En un marco de amplio consenso como el experimentado, era factible un discurso impugnador de la aventura malvinense? ¿¿Fue posible saltar este "cerco simbólico» y hacer audible la crítica intelectual? ¿Primó la prudencia en las declaraciones de estos intelectuales frente a esta inaudibilidad del discurso crítico? O, muy por el contrario, ¿hubo intelectuales que hicieron frente a la misma, aún a riesgo de su alienación de la sociedad misma? ¿Qué análisis o deducciones esgrimieron aquellos intelectuales que criticaron la Guerra de Malvinas?

Con el objetivo de intentar delinear respuestas tentativas y exploratorias para las preguntas planteadas, este artículo surcará a través de las descripciones, análisis y razonamientos de un variado grupo de intelectuales de izquierda que generalmente no son objeto de estudio de parte de los escasos abordajesacerca de la temática²: el grupo Punto de Vista, la revista Testimonio Latinoamericano y Néstor Perlongher ${ }^{3}$. Diversidad que representa variadas pertenencias ideológicas, disímiles trayectorias personales asociadas a la militancia, la representación de experiencias del «exilio

\footnotetext{
${ }^{1}$ Al respecto, nos enfrentamos a un primer problema «conceptual»: ¿cómo recortar el campo de la izquierda en Argentina?, entendiendo cabalmente que toda delimitación implica la jerarquización de ciertas características en desmedro de otras. En este caso en particular, la delimitación del espacio de izquierda no posee un criterio unívoco y claro, siendo la regla la existencia de límites difusos, ambiguos e inasibles. Ante esta dificultad, quizás la respuesta más simple a nuestro interrogante sea proseguir los pasos de sendos trabajos ineludibles para el racconto histórico de esta fracción: el estudio de Oscar TERÁN (1991) y la investigación de Silvia SIGAL (2002). El primero desde su análisis del nacimiento de la izquierda intelectual, y la segunda desde la intelligentsia contestataria o crítica como uno de los tipos de configuración histórica de la intervención intelectual, explicitan criterios de demarcación de esta fracción. ${ }^{2}$ Cabe indicar que no hay trabajos especializados que sistematicen el posicionamiento del firmamento intelectual de izquierda frente a la guerra de Malvinas. Sí se multiplican menciones, notas al pie, pero sin la profundidad analítica que el tema amerita. Dentro de estos comentarios o referencias, la mayoría se concentran en la célebre reyerta entre el Grupo de Discusión Socialista y León Rozitchner: nos referimos a: ROZITCHNER (2005) y a la Declaración del Grupo de Discusión Socialista, 10/05/1982.

${ }^{3}$ Este detalle no pretende ser exhaustivo y la elección de las experiencias remite únicamente a la extensión posibilitada por estas páginas. Al respecto cabe notar otras experiencias: Adolfo GILLY (1983); el libro de DABAT Y LORENZANO (1983), el folleto ¿Verdad o mística nacional?, de Carlos Alberto Brocato, repartido en mano y publicado en la revista Nueva Presencia en Abril 1982 y el artículo de Oscar Terán, publicado en agosto de 1982 en Le Monde Diplomatique, bajo el seudónimo de Carlos Ramírez, intitulado «Malvinas: la derrota, la locura y el mar», artículo incluido en TERÁN (2006).
} 
interno» o «insilio» y del "exilio externo» ${ }^{4}$, así como diversas implicancias de estas voces. Variabilidad que, lejos de constituirse en una debilidad metodológica, enriquece el análisis del cual es objeto este artículo5.

La guerra de las Malvinas sin lugar a duda constituyó -en su pluridimensionalidad- un quiebre e hito para la sociedad argentina, frente al cual resultó imposible quedar a resguardo, sin intervención, sin que tocase -en su apoyo o crítica-alguna fibra íntima. En el caso particular de las expresiones intelectuales de izquierda-como también lo haría para sus expresiones partidarias-Malvinas, a su vez, puede sopesarse como un hecho que puso a prueba sus estrategias de posicionamiento, las baterías teóricas que les sirvieron de fundamento y las diversas formas de compatibilizar este registro con las experiencias personales del exilio, la persecución y la desaparición de las cuales fueron objeto privilegiado todas las expresiones que pretendieran poner en cuestión el nuevo discurso autoritario ${ }^{6}$. De esta forma, entendemos que Malvinas puede entenderse como la condensación, cual catalizador, de nociones profundas del campo intelectual de izquierda argentino como Nación, Pueblo y

${ }^{4} \mathrm{Al}$ respecto, cabe indicar una precisión metodológica de relevancia. El par conceptual «exilio interno»/«exilio externo» 0 «exilio»/«insilio» lejos se encuentran de constituirse en conceptos claros y cristalinos para el campo de la historia reciente. Ahora bien, dada la imposibilidad -en virtud de la extensión limitada- de explicitar los fundamentos conceptuales que fundan la utilización de los mismos, es dable indicar que la utilización en el presente de dicho par conceptual obedece a su funcionalidad para indicar al campo intelectual de la izquierda argentina como un campo temporalmente escindido. ${ }^{5}$ Cabe, por último, señalar una serie de precauciones metodológicas. En primer lugar, por un obvio tema de extensión, el desarrollo de las tres experiencias intelectuales seleccionadas se ha realizado a expensas de un mayor desarrollo histórico y conceptual que remita y contextualice las trayectorias intelectuales, pertenencia político-partidaria, producciones culturales y las diversas luchas por la memoria de Malvinas. En segundo lugar, Asimismo, estas páginas conjugan la expresión de grupos de sociabilidad intelectual expresados en revistas institucionalizadas junto con expresiones desinstitucionalizadas o directamente individuales. Entendemos que este "desbalance» es igualmente fructífero y provechoso para la dinámica analítica pretendida al considerar el mayor abanico posible de «tipología» de expresiones: trayectos de pertenencia político-partidaria e ideológica; el insilio y exilio externo; grupos de sociabilidad intelectual e intelectuales individuales; entre otras.

Por último, la explicitación de estos posicionamientos, vale aclarar como resguardo analítico e historiográfico, no remiten ni echan manto de dudas sobre la dinámica de resistencia y oposición que oficiaron estos actores frente a los años de plomo. Asimismo, tampoco este artículo posee como espíritu el objetivo de realizar un juzgamiento ex post -de nula utilidad- de dichos posicionamientos bajo una semejanza a las argumentaciones post hoc ergo propter hoc.

6 Véase Beatriz Sarlo, «El saber del texto», Punto de Vista, n²6, abril de 1986. 
Democracia, y que entendemos -como hipótesis tentativa que excede este trabajodebe ser abordada para comprender las modificaciones acaecidas en dicha fracción del campo intelectual con la finalización de la última dictadura cívico-militar.

\section{LA SIGNIFICACIÓN DEL SILENCIO COMO PRUDENCIA INTELECTUAL. LA REVISTA PUNTO DE VISTA ANTE LA GUERRA DE MALVINAS}

El posicionamiento del grupo de intelectuales nucleados en torno de la revista Punto de Vista ${ }^{7}$ frente a la guerra de Malvinas posee varios condimentos que permiten avizorarlo como un excelente ejemplo de lo que podríamos denominar como la amalgama entre prudencia y crítica intelectual. Entre los meses de abril y junio de 1982, la revista Punto de Vista no emitió declaración, testimonio o palabra alguna sobre el conflicto malvinense de forma explícita. Recién habrá que esperar hasta terminado el conflicto, en el $n^{\circ}$ is de la revista en agosto de I982, para encontrar una manifestación respecto a lo acaecido en los meses precedentes.

Sin embargo, a esta «mudez pública» se le contraponía, según declaraciones de los propios Carlos Altamirano y Beatriz Sarlo, directores de la publicación, una activa crítica y oposición clandestina por intermedio de la circulación de un texto colectivo elaborado por el Consejo de Redacción de Punto de Vista y que transitaba subrepticiamente sumando apoyos diversos:

«Me acuerdo que redactamos en Punto de Vista un texto colectivo de repudio a la aventura militar, que era a su vez una declaración de apoyo a las gestiones de Pérez Esquivel (...) La oposición a la Guerra de Malvinas nos puso en comunicación con otra gente que suscribió esta declaración que circulaba clandestinamente de mano en mano (...) Jorge Goldenberg, Luis Priamo, Hilda Sábato, Leandro Gutierrez, todos conectados por el antimalvinismo, es decir por la denuncia de la guerra» (en: TRÍMBOLI, 1998:I6-17).

\footnotetext{
7 Surgida desde el mismo seno de la clausurada revista Los Libros, Punto de Vista fue fruto de un proceso de encuentros y conversaciones de sus tres fundadores -Beatriz Sarlo, Carlos Altamirano y Ricardo Piglia-. Creada en 1978 (y que concluiría con su n 90 en 2008) se presentaba como un espacio desde el cual se pretendía saltar el cerco impuesto por la dictadura, mediante la recomposición de los lazos intelectuales barridos por el terror. Se constituyó a la vez como espacio de difusión, como instrumento de actualización teórica, como cobijo de un grupo de intelectuales frente a la devastación y como impulso para la reconstitución del campo intelectual de izquierda.
} 
¿Cómo debe ser interpretado este silencio público? ¿Era factible trasladar esta oposición privada al espacio público? Quizás un atisbo de respuesta al espíritu que animó esta no explicitación pública puede encontrarse en las mismas palabras de Beatriz Sarlo en un libro del año 200 que recopila una serie variada de artículos intitulado Tiempo presente, notas sobre el cambio de una cultura. En uno de dichos textos - ¿iLa Voz universal toma partido?»-, Sarlo expresa la conmoción experimentada durante la escenificación de las pasiones colectivas en el marco de la guerra de Malvinas: «Nunca, ni antes ni después, me sentí tan ajena, tan salvajemente separada de la sociedad argentina como en los meses de la Guerra de Malvinas» (SARLO, 200I: 198).

Frente a la primacía de la unanimidad y el llamamiento por la unidad total del pueblo argentino, Sarlo puntualiza que el intelectual debía tener en cuenta las condiciones reinantes para la enunciación y audibilidad de su pensamiento, y no meramente el impulso propio de explicitar dicho discurso. De esta forma, el conflicto de Malvinas planteó -en sus palabras- la dificultad para el intelectual de convertir sus intervenciones en un discurso infructuoso e inaudible, situación creada por las condiciones precarias para el despliegue del quehacer propio del intelectual crítico. Bajo este sentido, ante esta imposibilidad de saltar el cerco simbólico para expresar la diferencia y la crítica, primó para los integrantes de Punto de Vista el sentido de prudencia. Vale decir, este silencio de sus páginas, en conjunción con su activismo clandestino durante el conflicto, puede entenderse sólo a la luz de la primacía de la prudencia por sobre la pulsión de la intervención crítica del intelectual; un impulso que sólo traería consigo la ruptura total con ese pueblo que se congregaba en la Plaza de Mayo, victoreando la decisión adoptada por el autodenominado Proceso de Reorganización Nacional:

«Quienes no participábamos del entusiasmo, con argumentos bastante sencillos por otra parte, estábamos más lejos que nunca del sentido común y de los deseos colectivos: en todos los aspectos éramos intelectuales alineados de la comunidad (...) Frente a la guerra, el discurso crítico fue impotente no sólo porque los medios habían construido el acontecimiento y profetizado la victoria (...) sino también porque el discurso crítico no tenía condiciones de audibilidad» (SARLO, 200I: 200).

Pero más allá de esta proto-explicación, ¿cómo interpretar este silencio? Esta prudencia a la cual se hacía alusión, ¿¿debe interpretarse en términos eminentemente negativos como inacción y pasividad aquiescente o acaso el mutismo en determi- 
nadas circunstancias reviste la condición de una acción plenamente crítica? Si bien responder a esta interrogación excede nuestro objetivo, es posible aventurar un atisbo de interpretación a la luz de la tesis sostenida por Hannah Arendt en su texto El pensar y las reflexiones morales (ARENDT, 1995). En este texto, haciendo alusión a la experiencia de los totalitarismos, destaca la importancia de saber interpretar la inmovilidad y los silencios en contextos donde el pensar es objeto de tan vasta e intensa presión simbólica. Así, dirá Arendt, detrás de la aparente mudez en estos escenarios, se esconde una profunda y activa significación y elocuencia. El silencio nunca tiene mayor sonoridad que en estos contextos. Cuando el escenario que nos circunda nos impele tan fuertemente a prestar ciega conformidad y seguidismo; cuando la violencia simbólica es de tal dimensión, la quietud y el silencio adquieren una nueva consideración, se convierten en resistencia y, por ella misma, en enteramente activa: «Cuando todo el mundo se deja llevar irreflexivamente por lo que todos los demás hacen o creen, aquellos que piensan son arrancados de su escondite porque su rechazo a participar llama la atención y, por ello, se convierte en una especie de acción» (ARENDT, I995:I36).

Finalmente, la explicitación del pensamiento de este grupo de intelectuales respecto a Malvinas -que durante el conflicto podría ser calificado como una compleja amalgama de silencio y prudencia intelectual-ocurre en el número is de la revista, en agosto de 1982, con el artículo de Carlos Altamirano «Lecciones de una guerra». De más está decir que estas palabras no poseen la misma significación que si hubiesen sido enunciadas durante el transcurso del conflicto armado, debido a que mutaron las condiciones no sólo de su enunciación sino -y principalmentede audibilidad de dicho discurso. Sin embargo, en dicho número perdura cierta prudencia que se ve expresada en la tapa de la misma revista, en la cual no se hace ningún tipo de mención al artículo de referencia sobre la guerra de Malvinas. El artículo -que posee la entidad de un editorial dado que se encuentra suscripto por todo el Consejo de Redacción- comienza con el reconocimiento del sismo que provocó el conflicto Malvinas al interior del campo intelectual y, por ende, la necesidad de encarar una reflexión en torno al mismo, aunque sin hacer alusión alguna a su silencio durante su transcurso ni a su activismo en la clandestinidad; "Punto de Vista no considera que esta temática pueda permanecer fuera del espacio de la revista, como reflexión sobre lo sucedido y sobre las posiciones que dividieron al campo intelectual» (ALTAMirano, I982: 3). 
El texto parte de la desmitificación de uno de los lugares comunes de ciertas lecturas omnipresentes durante el conflicto: la que versaba que la guerra y su triunfo llevaría al fin del Proceso avizorando un resultado final donde se establecía una curiosa diferenciación: bueno para la nación y malo para el régimen. En contraposición, Carlos Altamirano lee Malvinas de una forma bifronte, por un lado, como un manotazo de ahogado, como la última ratio desde la cual recomponer la legitimidad del régimen y recuperar la iniciativa política; en fin, como posibilidad de dotar de sobrevida a un régimen moribundo. Y, por otro lado, como la batalla final, como punto culminante y máxima expresión de la pulsión beligerante y mesiánica intrínseca al régimen, y cuyo antecedente Altamirano observa en la fallida intentona de guerra con Chile por el conflicto del canal de Beagle: «El operativo no se puso en marcha para iniciar la liquidación del proceso comenzado seis años atrás, sino para sacarlo del atolladero y conducirlo al cumplimiento de sus metas» (ALtamirano, 1982: 4).

Junto con esta primera desmitificación, el artículo emprende una segunda impugnación, en este caso, de la lectura errada e ingenua de vastos sectores de la izquierda que vieron en Malvinas la escenificación de una guerra antiimperialista (por ejemplo la mencionada posición del Grupo de Discusión Socialista en el exilio mexicano ${ }^{8}$. En este sentido, Altamirano adjudica esta visión no sólo a una mala evaluación de las circunstancias, sino también a la imposición por parte del Proceso del clivaje imperialismo-antiimperialismo como retórica de moda. Así, sin afirmarlo directamente, Altamirano establece que estos sectores se vieron presos del giro discursivo y actitudinal de aquel. Una nueva discursividad y simbología que lejos de responder a un impulso realmente antiimperialista, era funcional a una estrategia netamente pragmática para dotar de legitimidad a la causa y reco-

\footnotetext{
${ }^{8}$ Argumento estructural, asimismo, del posicionamiento de la totalidad de los partidos políticos de izquierda que, dicho sea de paso, implicó un apoyo a la incursión armada, bajo el prisma, justamente, de la primacía explicativa y simbólica del clivaje imperialismo-antiimperialismo. Por otro lado, si se tuviese que indicar cuál de los posicionamientos de intelectuales desde el exilio frente a la guerra de Malvinas ha sido más citado, aludido y analizado, no cabe la menor duda que se trata de la Declaración del Grupo de Discusión Socialista en el exilio mexicano, llevada a cabo el 10 de mayo de 1982. Nucleados en torno a la revista Controversia para el examen de la realidad argentina (1979-1981), su Declaración se encuentra estructurada a la manera de un pequeño estudio que tiene por objetivo no sólo demostrar la nula razón de aquellos que bastardean la causa, sino erigir la incólume e intemporal legitimidad intrínseca de la misma. En este marco, podemos inscribir el texto citado de León Rozitcher escrito a la luz de la Declaración del Grupo de Discusión Socialista y con el objetivo de demoler sus argumentos.
} 
ger apoyos; «En cuanto a los que se propusieron reapropiarse del conflicto para darle una orientación radical, asimilándolo a una guerra de liberación nacional, únicamente lograron encrespar sus propias declaraciones» (ALTAMIRANO, 1982: 4).

Sin embargo, a pesar de esa mirada crítica, en el artículo se reproducen varios de los lugares comunes de Malvinas. Además de resaltar el incalculable valor económico e innegable valor geopolítico de las islas Malvinas, Altamirano deja a salvo los justos y bondadosos intereses del pueblo que llenó la plaza ese 2 de abril. Así, mientras emprende la responsabilización del Proceso y de sectores que apoyaron la empresa, en el texto sobrevuela la desresponsabilización del pueblo, bajo cierta idea de dignidad intrínseca de la causa Malvinas: «el pueblo no necesitaba pagar por esta lección un precio tan alto» (ALTAMirano, 1982: 5).

De esta forma, el grupo de intelectuales nucleados en Punto de Vista se posicionó de una forma bifronte o dual: activismo y crítica subterránea a través de lazos de sociabilidad y comunicación con otros intelectuales de izquierda que se oponían a la guerra, así como ausencia de intervención intelectual explícita ${ }^{9}$-pública-, patentizado en la inexistencia de proclamas, solicitadas o edición alguna de la revista durante el conflicto. Declaración de principios que recién se cristaliza una vez terminado el conflicto en agosto de 1982.

El total mutismo (privado y público) podría explicar la complicidad o el apoyo, pero cómo explicar esta diferenciación entre la acción pública y la privada. ¿Cómo hacer inteligible estas dos caras? ¿Qué impidió hacer explícita esta crítica privada? La primacía del sentido de prudencia, en tanto cuidado del espacio intelectual institucionalizado que representaban a través de la revista como de condiciones de audibilidad de su discurso como intelectuales ante la presión simbólica existente en la dimensión espacial del exilio interno, evitaba de esta forma la generación de un nuevo «divorcio» con el pueblo, ese sujeto tan anhelado por la izquierda, $y$, muchas veces, tan esquivo.

${ }^{9}$ Cabe puntualizar, por ejemplo, que tampoco en el caso de otra de las revistas emblemáticas de la resistencia intelectual bajo la dictadura, la revista Crítica \& Utopía no hace declaración alguna en sus páginas respecto a la guerra de Malvinas, ni siquiera en el número 7/8 de julio/noviembre de 1982. 


\section{LA RECUPERACIÓN DE MALVINAS COMO JUSTICIA HISTÓRICA. EL POSICIONAMIENTO DE TESTIMONIO LATINOAMERICANO DESDE EL EXILIO ESPAÑOL}

Frente a la experiencia intelectual del grupo Punto de Vista en el exilio interno resulta, asimismo, interesante abordar el posicionamiento de otro grupo de intelectuales. Si los primeros transitan la tensión y la conflictividad entre una clara oposición a toda política del autoproclamado Proceso de Reorganización Nacional, amalgamada como posición ideológica e intelectual y la enorme presión simbólica, cultural y política por prestar ciega conformidad a la «aventura bélica» de las Islas Malvinas a través del sentido de prudencia, la revista Testimonio Latinoamericano ${ }^{10}$, cuyas cabezas visibles eran Álvaro Abos y Hugo Chumbita, se inserta al interior de las diversas polémicas en el exilio español de las corrientes del peronismo ${ }^{11}$.

Será en los números I2/13 y I4 donde la revista exprese su posicionamiento -no exenta de reyertas y discusiones internas- frente a la guerra de las Malvinas, mediante ediciones dedicadas casi exclusivamente a la contienda bélica. Cabe indicar que estos números poseen distintos escenarios de trasfondo (y, por lo tanto, de significación): el número I2/ı3 saldrá a la luz en el mes de abril ni bien iniciado el conflicto y, por lo tanto, en pleno éxtasis malvinero -el editorial intitulado «El Malvinazo de la Dictadura» representa plenamente ese estado de ebullición-; mientras que el número i4 se editará en el mes de julio, días después de la rendición, con la pretensión de generar un balance de la guerra.

En términos generales, Testimonio Latinoamericano, con muchos de sus argumentos similares y simétricos a los que despliega el Grupo de Discusión Socialista en el exilio mexicano, encarará una profunda defensa de la guerra, echando mano a una postura netamente nacionalista. Posición que se sustenta en la columna vertebral de la autosuficiencia de la causa Malvinas y de su valoración como núcleo del sentimiento nacional, como símbolo de la argentinidad que sólo puede ser

\footnotetext{
10 La revista Testimonio Latinoamericano se iniciaba hacia marzo/abril de 1980, bajo la dirección de Álvaro Abos, Hugo Chumbita y Jorge Bragulat, como uno de los emergentes de las discusiones y elaboraciones del exilio peronista en España, particularmente en Cataluña. En esta publicación, el peronismo de izquierda pasaba el tamiz no sólo a la revisión de la violencia como método, sino también a las razones de la derrota del campo nacional-popular y, en vistas de la construcción de un nuevo horizonte peronista, iniciaba un proceso de reconversión conceptual y revalorización de la noción de democracia al interior del peronismo

${ }^{11}$ Para una mayor profundidad, véase JENSEN (2005).
} 
bien comprendido si es visto "con ojos argentinos» (señalamiento directamente dirigido a la prensa e intelectualidad catalana que criticaron fuertemente el apoyo realizado por varias franjas de exiliados argentinos a la incursión bélica del Proceso).

En primer lugar, Abos y Chumbita impugnan la presunción según la cual apoyar la guerra de Malvinas implica necesariamente contribuir a la perpetuación del Proceso. En contrapartida, los editores de Testimonio Latinoamericano observan la guerra de Malvinas como un acontecimiento auspicioso que signa el comienzo del fin del proceso dictatorial. Así, el conflicto de Malvinas es sopesado como el suceso que desata tendencias centrífugas que el Proceso no puede manipular y que, por ende, contribuyen a la desintegración del mismo. Al recuperar Malvinas, el Proceso activa actores, sentimientos, símbolos y proclama alianzas que traicionan y desdicen su propia identidad y que sellan el inicio de su destrucción (argumento que también utilizarán diversas fuerzas de izquierda):

«Ese apoyo (las manifestaciones populares y el acompañamiento de los países comunistas, de Latinoamérica y los países del tercer mundo), si en lo inmediato salva la dictadura, en el fondo la condiciona y la desnaturaliza. El precio a pagar será muy alto» (TESTIMONIO LATINOAMERICANO, I982: 5).

Es más, Abos y Chumbita establecen que la profundización del conflicto armado no hace más que ahondar esta desfiguración del régimen, llevando estas contradicciones internas a su máxima expresión. Así, el apoyo a la recuperación de las islas Malvinas lejos estaba de constituir per sé una afirmación del régimen dictatorial, no hace más que allanar el camino hacia su final; un desenlace que se presenta a los ojos de Testimonio Latinoamericano como inexorable. Esta noción central se vuelve precaria si no es acompañada por otras dos tesis que conforman el trípode argumental que subyace al apoyo brindado por este grupo de intelectuales: por un lado, la valorización de la opinión y acción popular y, por otro lado, la entidad «temporal» del reclamo por las Islas Malvinas.

Comenzando por este último, Testimonio Latinoamericano propugna que para entender acabadamente la complejidad de la cuestión Malvinas es necesario distinguir entre «dos temporalidades», en cuya diferencia se asienta la alienación del actor respecto a la acción (o, en otros términos, la respuesta al interrogante ¿̨cómo entender el proceso mediante el cual se puede diferenciar el acto en sí respecto al actor que lo despliega?). Las dos temporalidades que deben discernirse son: una 
«temporalidad larga» del reclamo malvinense y una «temporalidad corta» de la vigencia del Proceso. Así, mientras que la dictadura cívico-militar es necesariamente circunstancial, el pedido por la soberanía argentina de las islas Malvinas es permanente, tal como analiza Rosana Guber (GUBER, 200I). En este sentido, siguiendo el análisis de Silvina Jensen, era imperativo discernir «entre una reivindicación nacional de un país que ha sufrido el colonialismo, que debe ser apoyada sin reservas, y la circunstancia transitoria de una dictadura militar» (JENSEN, 2005a). En esta jerarquía temporal, el deber llama a «apoyar sin reservas» una herida abierta desde I833 frente a la transitoriedad, coyunturalidad o accidentalidad histórica de la vigencia de una dictadura. Así, acto y actor corren por carriles opuestos, y se hace trizas -según Abos y Chumbita- la impugnación según la cual la ilegalidad del Proceso funda el deber de no acompañar la recuperación de las islas Malvinas.

«Sin embargo, la recuperación de las Malvinas, cualesquiera hayan sido las motivaciones coyunturales que la provocaron, las intenciones subjetivas y la ilegitimidad de los actores, es un acto de justicia histórica. Así lo han visto todos los pueblo latinoamericanos» (TESTIMONIO LATINOAMERICANO, 1982: 5).

Este imperativo de diferenciación entre estas dos «temporalidades» finalmente no resulta más que la puesta en práctica del sentido común del «pueblo». Así, Abos y Chumbita encuentran en la conducta popular frente a Malvinas un núcleo de buen sentido, que lejos se encuentra de poder ser cooptado por el lenguaje y la propaganda dictatorial. En este sentido, el «pueblo» supo discernir entre la legitimidad de la causa y la ilegalidad del Proceso y ganó las calles - una espacio público hasta ese momento vedado- sabiendo que debía «disputarle la autoría» de esta recuperación a los militares. El pueblo se sabía el dueño legítimo de la causa. Desde este punto de vista, para Abos y Chumbita, al poner el acento en el «buen sentido» del pueblo, es plausible rescatar los hechos del Malvinas «del fango y del ridículo»; lugar donde los ubica la mirada eurocentrista, maniquea y racionalizante de muchos intelectuales. De esta forma oponerse a Malvinas es darle la espalda al anhelo popular:

«El pueblo no se dejó arrebatar sus banderas. Una conciencia histórica forjada en muchos combates resistió las manipulaciones, las presiones y las ceremonias de la confusión. El pueblo tuvo en claro a quién enfrentaba: al imperio agresor y su aliado yanqui, incluidos los personeros locales» (TESTIMONiO LATINOAMERICANO, I982: 7). 
Al fundar la legitimidad de la guerra de Malvinas en el logro de un profundo sentimiento y anhelo popular, a pesar de ilegalidad del Proceso, Abos y Chumbita construyen la identificación de la causa Malvinas con el núcleo de la argentinidad. Así, Malvinas no sólo es una causa popular, sino nacional. Y aquí radica para los editores de Testimonio Latinoamericano la ceguera de los detractores de la guerra: Malvinas se vuelve sólo inteligible para aquellos que la evalúan a través de una lente auténticamente asentada en la tradición popular argentina. En este tono, por momentos francamente virulento, se inscribe la defensa del apoyo a la Guerra de Malvinas por Testimonio Latinoamericano. En este sentido, la miopía de los censuradores los convierte en anti-populares y anti-nacionales.

Malvinas deviene - para Álvaro Abos y Hugo Chumbita- una causa suprapolítica, en tanto su entidad como histórico anhelo popular y como hito de la usurpación colonial antecede y supera ampliamente cualquier coyuntura, entre ellas una dictadura militar, ya que forma parte del núcleo de la argentinidad. Argentinidad vívida y convocante para el exilio externo.

\section{EL QUEHACER INTELECTUAL DESDE LOS MÁRGENES: NÉSTOR PERLONGHER. LA DIATRIBA DESDE EL EXILIO Y SU POLÉMICA CON LA REVISTA SITIO}

¿Por qué seleccionar a un poeta y ensayista como Néstor Perlongher como muestra de conducta desde el exilio externo frente a la guerra de Malvinas, más aun tratándose de un intelectual que generalmente no sobresalió -y muchas veces, ni siquiera es nombrado- en las crónicas de la época y en los trabajos especializados? ¿Por qué producir una suerte de salto en la lógica del devenir analítico incluyendo un intelectual «a solas»?

El caso de Néstor Perlongher resulta fructífero no tanto por la audibilidad de su crítica a la guerra, sino por la profundidad de los argumentos que despliega para sustentar su oposición, desplegando nudos conceptuales concordantes con los argumentos expuestos por León Rozitcher y el folleto de Carlos Alberto Brocato $^{12}$. Subsidiariamente, posee el condimento adicional de su doble condición de

\footnotetext{
${ }^{12}$ Se trata del folleto ¿La Verdad o Mística Nacional? bajo la autoría del denominado Círculo para la Formación de un Espacio Independiente, encabezado por Carlos Alberto Brocato, antiguo director de la célebre revista La Rosa Blindada junto a José Luis Mangieri y de pasado en la militancia trotskista.
} 
exiliado: no sólo sufrió la persecución ideológica como intelectual de izquierda, sino que también a ello le adiciona su condición de «minoría sexual» e integrante de antaño del Frente de Liberación Homosexual (FLH) ${ }^{13}$.

Néstor Perlongher poeta, ensayista y ex-militante trotskista, plantea su peculiar visión de la guerra Malvinas desde su estancia en Brasil por intermedio de un artículo -en formato proclama- intitulado «Todo el poder a Lady Di. Militarismo y anticolonialismo en la cuestión de las Malvinas ${ }^{14}$, publicado al unísono en un diario de Bahía y en el número I2 de la revista feminista Persona en Argentina bajo el seudónimo de Víctor Bosch, publicación ésta última de escasa tirada y de edición irregular dirigida por María Elena Oddone.

Perlongher emprende, por intermedio de un lenguaje directo, llano y plagado de sarcasmos e ironías, una crítica franca a la guerra de Malvinas y la responsabilización de todos los actores que, mediante su apoyo explícito o su silencio, la sustentaron; haciendo sí un mayor foco en desnudar el sinrazón del apoyo a la guerra, principalmente de la izquierda partidaria.

«Resulta por lo menos irónico comprobar cómo la ocupación militar de las Malvinas (...) ha permitido a una dictadura fascistizante y sanguinaria como la Argentina agregar a sus méritos los raídos galones del antiimperialismo» (PERLONGHER, [1982] 1996: 178).

Con estas palabras inicia Perlongher su proclama, en las cuales ya se expresa una de sus ideas medulares respecto a la guerra: el falso canto de sirenas del antiimperialismo. Imán que congregará los más disímiles e impensados sectores, entre ellos a la CGT, los partidos políticos mayoritarios y el arco partidario de la izquierda. En

En dicho folleto se expresa una crítica explícita, cruda y sin rodeos a la guerra de Malvinas. Así, el folleto aborda estos lugares comunes que rodean la aventura malvinense en buscar de emprender su desnaturalización y, por ende, decretar la falsedad de toda legitimidad de la empresa malvinense. ${ }^{13}$ El Frente de Liberación Homosexual nace en agosto de 1971. Vivió su apogeo entre 1972 y 1974 , con la edición de Somos, primera revista homosexual de América Latina y del escrito Sexo y Revolución, síntesis programática del movimiento. Ya con la instauración del Proceso y su plan sistemático de desaparición de personas se aniquilaba todo el accionar del FLH. Éste propiciaba la llegada de un momento histórico donde era necesario realizar una revolución que barra simultáneamente con el sistema económico y político que sustenta las bases ideológicas sexistas de nuestra sociedad. De esta forma, el sexo era entendido en sí mismo como una cuestión política. Se autodefinía como anticapitalista, antiimperialista y antiautoritario.

${ }^{14}$ Véase la reproducción de las publicaciones originales en la compilación: PERLONGHER ([1982] 1996). 
este sentido, se vuelve a presentar como nudo central la retórica del colonialismo y el clivaje imperialismo/antiimperialismo como juego del lenguaje y como estética a la cual se plegaron los actores políticos y sociales antes opositores, silenciados y perseguidos. Nuevamente, el recurso del colonialismo y el antiimperialismo vuelve a revelarse como profundamente productivo para el Proceso gracias a lo que Ernesto Laclau podría llamar su capacidad para convertirse en un «significante vacío». En este sentido, Perlongher no sólo echa por la borda la posibilidad de calificar de «antiimperialista» a la guerra de Malvinas por su inaplicabilidad para el caso de su empuñadura por una dictadura, sino fundamentalmente, por el anacrónico -para este caso- y vago uso de la concepción del imperialismo de cuño leninista, según el cual en el caso hipotético de un conflicto armado entre una país atrasado y otro avanzado, se debía cerrar filas detrás del primero, «como si un amo pobre fueses menos despótico que uno rico» (PERLONGHER, [1982] I996: I79).

Conjuntamente a esta desmitificación, Perlongher impugna toda posible enarbolación de una «abstracta territorialidad» como fundamento del conflicto, así como también toda lectura del mismo en términos de una recuperación de espacios públicos anteriormente vedados, plausibles de ser utilizados para verter consignas antidictatoriales. En este sentido, resulta impensable para Perlongher apoyar la guerra de Malvinas en función de la ilusión democrática derivada de la apertura momentánea del espacio fundacional de la Plaza de Mayo y del espejismo del diseño de un nuevo mapa político sucedáneo. Un hipotético triunfo en la guerra, lejos de colaborar para el derrumbe del Proceso, sellaría su tan ansiada pretensión de eternidad. Aquí, Perlongher reproduce la misma calificación de la guerra como «manotazo de ahogado», ya observada en el artículo de Carlos Altamirano. La guerra de Malvinas es el único camino posible que encara un régimen que desea reagrupar sus fuerzas, ganar el centro de la escena política y evitar así su derrumbe.

Pero quizás más allá de los argumentos puntuales que expresa Perlongher para rebatir el apoyo a la Guerra de Malvinas, su relevancia medular para nuestra mirada estriba en su labor de responsabilización de aquellos actores que sustentaron la viabilidad de la guerra. En términos generales, Perlongher deshecha de raíz enarbolar la «bondad o buena voluntad» del pueblo; «las castigadas masas argentinas (o al menos considerables sectores de ellas) se embarcan en la orgía nacionalista y claman por la muerte» (PERLONGHER, [I982] I996: I79).

Si Perlongher dirige su primera mirada inquisidora hacia las masas que, olvidando las masacres y saqueos sufridos, despliegan estas ansias de guerra y milita- 
rismo, la crítica más densa se dirigirá a la conducta de la izquierda partidaria. En sus breves páginas, se multiplican las alusiones al seguidismo de los partidos de izquierda, haciendo especial hincapié en la conducta del Partido Comunista (PC) -que Perlongher atribuye a la importancia cuantitativa que adquirió la uRss como comprador de las exportaciones argentinas- y del trotskista Partido Socialista de los Trabajadores (PST). Rotundamente, Perlongher encuentra la explicación principal para tal curioso posicionamiento en la histórica fascinación de la izquierda respecto a las masas. Dicho embrujo, que tiene una profunda genealogía que nos retrotrae a la cuestión peronista, termina por cegar la conducta de los partidos de izquierda. Nuevamente aquí, como en el caso del mencionado folleto de Carlos Brocato y las palabras de León Rozitchner, se recurre a la tesis del seguidismo popular como hipótesis explicativa monocausal de la conducta de la izquierda; ¿Cómo explicar el apoyo brindado por partidos y movimientos de izquierda ajenos a dicha carga simbólica e histórica?

«La claudicación de las izquierdas ante los delirios patrioteros de la dictadura es ya una constante: ellas se dejan llevar (...) por el entusiasmo de las concentraciones de masas, sin percibir cuando ellas resultan en una legitimación del régimen» (PERLONGHER, [1982] I996: 177).

Pero, finalmente, Perlongher recurre de forma medular, más allá de los errores estratégicos e incongruencias conceptuales que el apoyo a la guerra acarrea, a un argumento de tinte ético: su completa aversión respecto al militarismo. El elevado costo humano que toda guerra trae consigo es el detonante de su oposición: «El sólo hecho de que guapos adolescentes, en la flor de la edad, sean sacrificados (o aún sometidos a las torturas de la disciplina militar) en nombre de unos islotes insalubres, es una razón de sobra para denunciar este triste sainete» (PERLONGHER, [I982] I996: I78).

«En medio de tanta insensatez, la salida más elegante es el humor: si Borges recomendó ceder las islas a Bolivia y dotarla así de una salida al mar, podría también proclamarse: todo el poder a Lady Di o El Vaticano a las Malvinas, para que la ridiculez del poder que un coro de suicidas legitima, quede al descubierto. Como propuso alguien con sensatez, antes que defender la ocupación de las Malvinas, habría que postular la desocupación de la Argentina por parte del autodenominado Ejército Argentino» (PERLONGHER, [1982] 1996: I80). 
Resulta asimismo interesante para la presente investigación traer a colación -a manera de breve excursus - un debate que, si bien se despliega a posteriori de concluida la guerra de Malvinas ${ }^{15}$, representa un sugestivo intercambio de miradas, en este caso entre el mismo Néstor Perlongher y los intelectuales nucleados alrededor de la revista Sitio ${ }^{16}$.

En su segundo número, editado hacia fines del año 1982, los miembros de la revista presentan un artículo colectivo bajo el título «Las Malvinas Argentina. Del trabajo a la guerra y de la guerra al trabajo ¡Argentinos a recomponer! » ${ }^{17}$. Quizás la mayor peculiaridad de este artículo sea la diferencia temporal y contextual entre las condiciones de su producción y el marco de su edición. Vale decir, el artículo de referencia, según las mismas expresiones vertidas en él, fue escrito en el fulgor del 2 de abril para el número que se encontraba a punto de salir a la luz, con lo cual refleja acabadamente la visión de este grupo de intelectuales respecto al conflicto, pero también plantea una mirada, un análisis afincado en un escenario disímil respecto a fines de 1982 donde se da su publicación. Es más, imaginando este interrogante medular, gran parte de los párrafos de dicho artículo (además de la discusión en torno al poema de Jorge Luis Borges «Juan López y John Ward») discurre en esta discusión respecto a las razones que los llevan a publicar dichas palabras. En primer lugar, se escribe desde el sobrecogimiento que provocó la guerra. En segundo lugar, se escribe para evitar el olvido de Malvinas. Seguidamente, se escribe porque -normativamente- la literatura no debe callar ante este tipo de

${ }^{15}$ Entendemos que la introducción de esta polémica entre Perlongher y la revista Sitio representa un salto metodológico y de registro analítico en la estructura del presente trabajo. Sin embargo, la reconstrucción de esta reyerta es útil para explicitar cómo los fundamentos simbólicos, políticos, culturales e ideológicos que llevaron al apoyo a la guerra no sólo no eran circunstanciales o atados a lógicas superfluas sino que se afincaron en nociones, conceptos y lugares caros a diversas tradiciones políticas de las izquierdas. Sólo así es comprensible que pasado el fulgor del conflicto bélico, la revista Sitio continúe reproduciendo un cúmulo de argumentos en su defensa.

${ }^{16}$ Esta revista ve la luz de su primer número hacia finales de 1981 y se extenderá hacia 1987, editando sólo siete números. Siguiendo a Roxana PATIÑO (2006), puede decirse que la misma se inserta en términos generales en el campo intelectual de izquierda, pero particularmente en el campo literario. El grupo nuclear de la revista lo componían Ramón Alcalde, Eduardo Grüner, Jorge Jinkis, Luis Thonis, Luis Gusmán, Mario Levin y Héctor Grisafi y reconoce su antecedente inmediato en la revista Literal (1973-1977).

${ }^{17}$ El artículo aparecía firmado por Alcarde, Grisafi, Grüner, Gusmán, Jinkis y Savino, «Entredichos: Las Malvinas Argentina. Del trabajo a la guerra y de la guerra al trabajo iArgentinos a recomponer!», Sitio, $\mathrm{n}^{\circ} 2,1982$. 
sucesos: la literatura debe intervenir; Malvinas no puede significar un aplazamiento de la literatura. Y, finalmente, se escribe porque Malvinas significa un nuevo inicio, la apertura de un nuevo ciclo que «forzosamente nos dejaría en relaciones sociales nuevas» (sitio, 1982: 4). De esta forma, se debe hablar de Malvinas justamente porque después de Malvinas ninguno es el mismo: hay nuevos lectores, nuevos autores, nuevos fines y hasta una nueva eficacia literaria:

«Desembarcar, no podía: desembarcaron; consolidar una cabecera de playa era imposible, la consolidaron: a Puerto Argentino, no llegarían: llegaron; jamás nos rendiríamos, nos rendimos. La guerra había terminado. La primavera sudamericanista, anticolonialista, unión nacional, huyó al primer soplo del cierzo de la derrota. Ahora a enmendarnos» (sITIO, 1982: 45).

Será justamente en respuesta a este artículo que posteriormente, en el tercer número de la revista en 1983, Néstor Perlongher -asiduo colaborador de la mismalanzará una fuerte diatriba, a través de su artículo «La ilusión de unas islas», enviada desde su exilio en San Pablo. En dicho artículo, mediante la prosa herética, polemista y profundamente irónica que lo caracterizaba, Perlongher señala -como eje de la crítica $^{18}$ - que la revista Sitio se inserta al interior de un patriotismo de carácter infantojuvenil e ilusorio que finalmente «discute (...) por la posesión de unos desiertos (de los que al parecer no puede desertarse)» (PERLONGHer, 1983: 43). De esta forma, Perlongher nuevamente recurre a una fuerte crítica a toda posición que se asiente sobre las arenas movedizas del territorialismo o de la geopolítica, ya que de por sí resulta ilusoria toda atadura a un suelo, a un espacio, a una geografía determinada.

En el mismo número de la revista, se encuentran los artículos en respuesta de parte de los integrantes de Sitio a esta crítica. En primer lugar, aparece el texto de Jorge Jinkis intitulado «A la tibia musa, de un vate desencantado». Este artículo se estructura en base a dos tópicos medulares. Por un lado, la discusión por el signifi-

${ }^{18}$ Si bien éste resulta el principal resorte de la crítica emprendida, Perlongher asimismo despliega un conjunto de críticas secundarias de tono francamente mordaz respecto de las afirmaciones vertidas como ser que el Estado argentino no había conocido en este siglo guerra alguna, a lo cual mordazmente Perlongher señala, «que el Estado Argentino -espectador neutral- no ha conocido, en este siglo, guerras. Debe referirse, pensamos, a las guerras limpias (libradas, según las reglas de las artes marciales, entre Estados Soberanos)»(PERLONGHER, 1983: 47). 
cado y funcionalidad de las palabras, cuestión que discurre como combate estético y literario, y que finalmente no hace más que conformar el entorno desde el cual emerge el real señalamiento del autor: la incomprensión de Perlongher respecto a la palabras vertidas: "Así que abrevio: no entendiste ni jota» (JINKIs, 1983: 50). En síntesis, Jinkis imputa a Perlongher o bien de una incomprensión deliberada del tono sarcástico e irónico que desplegaban las hojas de Sitio o directamente del no entendimiento del mismo, estableciendo de esta forma que la oscuridad de un enunciado sólo es propiedad de quién lee y no de quién enuncia.

El segundo tópico -y podríamos decir, finalmente, el trasfondo de toda la respuesta de Sitio- refiere a la imputación hecha por Perlongher respecto a que los integrantes de la revista se encuentran encadenados a un pensamiento territorialista ilusorio. Frente a lo cual, Jinkis retraduce tal recriminación en la reyerta entre exilio interno y exilio externo, tratando de identificar sin más esta crítica a una típica operación o recurso de los exiliados, los cuales (en tono obviamente irónico) pueden, en razón de su constitutivo desgarramiento territorial, hablar libres de ataduras. Sin embargo, Jinkis señala que esta negación de la pertenencia territorial de la que hace gala Perlongher (y todo exiliado) es meramente una pose estética y política, ya que su "pasión brasileña", en obvia alusión a su residencia, es tan territorialista como la desplegada por cualquier integrante de Sitio: «Vayamos al grano: la brasileña pasión es un pasión no menos argentina, argentinísima, un lugar donde el alma delicada del liberalismo progre ha encontrado en estos últimos años el clima tibio en el que pueden florecer sus manifestaciones expresivas» (sıтіO, 1983: 50-5I).

Exactamente este mismo tono de respuesta pero con una prosa más virulenta y directa será desplegado por Ramón Alcalde en su texto "Ilusiones de isleño». Allí, luego de reconocer que "Perlongher ha sido duro con nosotros» (ALCALDE, I983: 52), señala que Perlongher los ha subvalorado rápidamente al sindicarlos como sujetos del engaño patrioteril. Subvaloración que utiliza como soporte, recurrentes juegos de palabras y subversiones del lenguaje, que no hacen más alimentar una escritura sumamente elíptica, que termina por mal informar al lector, tergiversando de esta manera las palabras vertidas por los integrantes de Sitio ${ }^{19}$. Más allá

${ }^{19}$ En palabras del propio Alcalde: «Ante todo me parece imperdonable que se nos presente como si en algún momento hubiéramos creído que la intención de la Junta fue llevar hasta sus últimas consecuencias el enfrentamiento contra el imperialismo (...) o que estuviera dispuesta a cumplir en lo interno las transformaciones políticas y económicas» (ALCALDE, 1983: 52). 
de estos señalamientos respecto a la calidad prosística de Perlongher, se trasluce otro cuestionamiento de mayor relieve directamente relacionado con su código político, ético y estético. Alcalde, de esta manera, impugna el espíritu moralizante de Perlongher, el cual lo lleva a «un anarquismo estetizante» (ALCALDE, 1983: 53), que no hace otra cosa que lanzar diatribas contra el Estado, la guerra, la geografía, la historia, el patriotismo, entre otros.

Pero nuevamente, al igual que lo observado en el artículo de Jorge Jinkis ${ }^{20}$, el debate termina transmutándose en la fractura del campo intelectual entre exilio interno y exilio externo. El punto de partida de esta transmutación será la afirmación de Alcalde respecto a que detrás de la prosa de Perlongher se esconde un reproche velado típico del exilio que se podría estructurar de la siguiente forma: «címo han cambiado desde que me fui?» (sitio, 1983: 53). Interrogación a la cual el mismo Alcalde responde:

«Es verdad. Cambiamos. En parte, nos cambiaron; pero, mucho más, quisimos cambiar o dejarnos cambiar. Si no lo hacíamos, nos quedábamos solos. Solos de quienes nos interesan. De lectores reales o imaginados. Solos, en esa monserga del exilio interior, de la catacumba, novedosísima argucia que no define nunca el lugar de la expulsión» (ALCALDE, 1983: 53).

A partir de la necesidad de explicitación de la célebre frase «Los sobrevivientes ¿no lo somos todos?» (ALCALDE, 1983: 54), Alcalde retoma la senda transitada por las reyertas Hecker/Cortazar y Terragno/Bayer ${ }^{21}$, desplegando nuevamente estrategias maniqueas de victimización y culpabilización. En este marco, el artículo -con un tono francamente virulento- parece convertir así al exilio en la causa de la imposibilidad de compresión de la envergadura y funcionalidad de la guerra de las Malvinas, entendimiento sólo asequible «a los que se quedaron»:

${ }^{20}$ Esta misma tesitura y tonalidad se vislumbra en el apartado especial «Del Exilio», también contenido en el tercer número de Sitio. Allí, el texto del mismo Jorge Jinkis «La Argentina, tango-canción. Para desmontar un discurso", plantea una fuerte crítica a la figura del exiliado y su intervención privilegiada, haciendo alusión al número doble $n^{\circ}$ 420/421 de Les Temps Modernes -específicamente a la figura de David Viñas-, a León Rozitchner y Juan José Sebreli. En las mismas aguas navega el artículo de Eduardo Grüner «La Argentina como pentimento».

${ }^{21}$ El tema recurrente y medular de estos debates que surcaron -en muchos casos con inusual virulencia, tanto que marcaron durante la década de 1980 el campo intelectual argentino- la intelectualidad de izquierda es la entidad del exilio (tanto «insilio» como exterior) y su significación. 
«Sé que dejando territorio argentino no lo he de encontrar (la forma justa de escritura para ese lector), o por lo menos que el abandonarlo no me lo garantiza ni me lo facilita. A otros posiblemente si. (...) De todas maneras, si me fuera, no estaría mirando con el rabillo del ojo hacia atrás (...) No vivió nuestras ilusiones. Tampoco el odio, la humillación, el dolor, que vivimos los de Sitio» (ALCALdE, 1983: 55).

Sin embargo, más allá de estas diatribas que terminan por secundarizar la cuestión Malvinas, en dicho trasfondo emerge tímidamente una opinión explícita sobre la guerra, que recrea, una vez más, los lugares comunes ya vislumbrados en los anteriores actores: el desborde de sentido, la autosuficiencia de la causa y la primacía de una interpretación antiimperialista del conflicto armado.

Ramón Alcalde es explícito al manifestar que una de las tareas de la revista Sitio justamente era impedir que se encubra el «verdadero sentido» de Malvinas; una significación plenamente anticolonialista, antiimperialista y forjadora de la unión de Latinoamérica y todas las tierras oprimidas: «Sólo que nos negamos a que se encubra todavía más el sentido que para Argentina, Hispanoamérica, el mundo colonial, las clases oprimidas de los mismos países centrales, cobró la guerra una vez trabada» (ALCALDE, 1983: 56). Este nuevo sentido se revela como útil y fructífero dado que inserta a la Argentina como país dependiente en una guerra contra las potencias imperialistas por antonomasia, haciendo realidad el mentado sueño de la unidad de los países oprimidos. En esta significación estriba la dejadez o secundarización respecto de las intenciones y circunstancias que le dieran surgimiento. De esta forma, el desborde de sentido y la autosuficiencia de la causa se fundan y se complementan mutuamente, tal como también observaremos en las palabras del Grupo de Discusión Socialista y los diversos partidos:

«Mis ilusiones personales sobre la guerra, en las cuales, sin embargo, sé que no estoy sólo, son dos: I) cualesquiera hayan sido las intenciones, las circunstancias y el modo como se la inició y se la llevó a cabo, la guerra pudo ganarse y estuvo a punto de ser ganada, pero fue vendida; 2 ) esta guerra entre un país dependiente y las dos mayores potencias imperialistas (...) implicaba forzosamente la aparición de condiciones sociales nuevas» (ALCALDE, 1983: 56). 
Pero nuevamente la tríada estaría incompleta si no se deja traslucir un tercer elemento de profunda importancia como hito constitutivo de la izquierda en Argentina: la lectura en clave antiimperialista. De esta manera, el clivaje imperialismo/antiimperialismo se encadena sucesivamente con otros clivajes como ser nacionalismo/cipayismo y liberación/dependencia, los cuales conforman el encadenamiento de sentido gracias al cual se apoya la guerra, y hacia los cuales dirigía su prosa herética Néstor Perlongher:

«Personalmente no soy belicista. Las guerras no me gustan. Pero si mi país se encuentra embarcada en una, prefiero que la gane y no que la pierda (...) El lujo del pacifismo humanista, abstracto, me lo podré permitir cuando mi país se haya liberado, lo hayamos liberado» (ALCALDE, 1983: 56-57).

De esta forma, en la pluma de Néstor Perlongher se observa una expresión intelectual de profunda crítica y aversión no sólo a la propia guerra de Malvinas como hecho político y cultural, sino fundamentalmente hacia la sociedad toda por el apoyo a esta aventura de la dictadura. Este posicionamiento herético se produce desde la más profunda extrañeza y ajenidad respecto a esa sociedad en general, pero particularmente respecto a las diversas expresiones de la izquierda argentina que también se ven arrastradas por la marea malvinense.

De esta forma, la izquierda -según Perlongher- embelesada por el canto de sirenas del imperialismo, el territorialismo y el seguidismo popular, presta su ciega conformidad a una aventura (y a un régimen que lo impulsa) que lejos está de responder a su mandato histórico, político e ideológico, sino que las contradice y anula. Sin embargo, finalmente, este completo divorcio -cual francotirador-que expresa Perlongher respecto a Malvinas es la expresión ética de su aversión por el militarismo; violencia hacia «afuera» que, siguiendo las palabras de León Rozitchner, no sería más que la continuidad por otros medios de la violencia «hacia adentro", de la cual las diversas expresiones políticas y culturales contestatarias fueron objeto privilegiado del accionar de la última dictadura cívico-militar. 


\section{CONSIDERACIONES FINALES}

A lo largo del desarrollo que acabamos de realizar, creemos que ha quedado establecido cómo la guerra de las Malvinas se constituyó en un hecho que puso a prueba las estrategias de posicionamiento de los intelectuales afincados en la izquierda argentina y las baterías teóricas que les sirvieron de fundamento. Fundamentos que claramente no residen en consideraciones superficiales o epidérmicas, tales como el mero seguidismo popular; sino que estriban en postulados ideológicos de profundo anclaje que transversalmente se encuentran presentes -en distintas graduaciones y modos- en las diversas corrientes de pensamiento que podríamos considerar perteneciente al campo de la izquierda y que forman parte de los trayectos de militancia de los intelectuales aquí analizados.

Este artículo ha pretendido, de forma somera, explicitar y analizar, al menos inicialmente, los posicionamientos y las razones esgrimidas para su fundamento de tres actores de la intelectualidad de izquierda. Elecciones que entendemos que poseen diversas fortalezas analíticas al privilegiar el mayor abanico posible o pluralidad en tanto disímiles trayectos de pertenencia político-partidaria e ideológica, el insilio y exilio externo, grupos de sociabilidad intelectual e intelectuales individuales, entre otras.

Muestras que sirven como signo de la conmoción causada por la guerra de Malvinas en la intelectualidad de izquierda y frente a la cual la reacción o posicionamiento lejos estuvo de ser unánime, demostrando un abanico de razonamientos, explicaciones y modalidades de intervención sumamente variado: silencio público y oposición privada; diatriba pública; apoyo público; críticas intra-intelectualidad en el exilio, entre otros. Variabilidad que se sustenta en cada caso en procesos de jerarquización disímil entre registros subjetivos de la experiencia personal, axiomas ideológicos afincados en trayectorias político-partidarias y el rol y función del intelectual.

Adicionalmente, a través de este abordaje el trabajo procuró colaborar en la explicitación de una de las temáticas ausentes en la bibliografía especializada del abordaje de la guerra, como en los anales historiográficos del campo intelectual argentino; invisibilidad que creemos que actúa como signo de su relevancia. Este signo nos expresa el status que posee nuestro tema de investigación: su persistencia como espacio vedado a la interpretación y la re-elaboración; una trama no problematizada de nuestra historia, y menos aún explicitada en toda su dimensión. Esta invisibilización de los posicionamientos frente a la guerra de Malvinas, a pesar de la profusa literatura existente sobre la contienda bélica, tiene una funciona- 
lidad determinada: el olvido deliberado de un hecho histórico que actúa como núcleo que condensa profundas ambigüedades, contradicciones, resquemores y opacidades. Así, la invisibilización de nuestro objeto de investigación es lo que sustenta -paradójicamente-su relevancia: la imperiosa necesidad de su indagación, reconstrucción y análisis.

\section{Bibliografía}

ALCALDE, RAMÓN (1983): «llusiones de isleño», JENSEN, SILVINA (2005): «Vientos de polémica en CataSitio, n³. luña: Los debates entre los de adentro y los de afuera ALTAMIRANO, CARLOS (1982): «Lecciones de una Guerra», en: Punto de Vista, n¹5. de la Argentina de la última Dictadura militar», en: HMiC: història moderna i contemporània, $n^{\circ} 3$. ARENDT, HANNAH (1995): «El pensar y las reflexiones morales», en: De la historia a la acción, BarceIona, Paidós. JENSEN, SILVINA (2005): «Identidad, derrotero y debates en el exilio peronista en Cataluña (19761983)», en: Hispania Nova, nº 5.

CÍRCULO PARA LA FORMACIÓN DE UN ESPACIO INDEPENDIENTE (1982): ¿La Verdad o mística nacional?, Buenos Aires.

DE DIEGO, JOSÉ LUIS (2003): ¿Quién de nosotros escribirá el Facundo? Intelectuales y Escritores en Argentina (1970-1986), La Plata, Ediciones Al Margen.

JINKIS, JORGE (1983): «A la tibia musa, de un vate desencantado», en: Sitio, $n^{\circ} 3$.

LORENZ, FEDERICO (2006): Las Guerras por Malvinas, Buenos Aires, Edhasa.

PALERMO, VICENTE (2007): Sal en las heridas. Las Malvinas en la cultura argentina contemporánea, Buenos Aires, Sudamericana.

DECLARACIÓN DEL GRUPO DE DISCUSIÓN SOCIALISTA (1982).

PATIÑO, ROXANA (2006): «Revistas literarias y culturales argentina de los 80», en: Ínsula, n 715-716. GUBER, ROSANA (2001): ¿Por Qué Malvinas? De la causa nacional a la guerra absurda, Buenos Aires, Fondo de Cultura Económica. PERLONGHER, NÉSTOR (1983): «La Ilusión de una islas», en: Sitio, $n^{\circ} 3$.

JENSEN, SILVINA (2007): «iGuerra antiimperialista o maniobra dictatorial? El dilema del exilio», en: Puentes, $n^{\circ}$ 20, La Plata.

PERLONGHER, NÉSTOR ([1982] 1996): « Todo el poder a Lady Di. Militarismo y anticolonialismo en la cuestión de las Malvinas», en: Prosa plebeya. Ensayos 1980-1992, Buenos Aires, Colihue. 
TESTIMONIO LATINOAMERICANO (1982).

ROZITCHNER, LEÓN (2005): Malvinas: de la guerra sucia a la guerra limpia. El punto ciego de la crítica política, Buenos Aires, Losada.

SARLO, BEATRIZ (2001): «iLa Voz universal toma partido?», en: Tiempo Presente. Notas sobre el cambio de una cultura, Buenos Aires, Siglo XXI. SARL0, BEATRIZ (1986): «El saber del texto», en: Punto de Vista, n² 26, Abril.

SIGAL SILVIA (2002): Intelectuales y poder en Argenti- TRÍMBOLI, JAVIER (1998): La Izquierda en Argentina,

na. La década del sesenta, Buenos Aires, Siglo XXI. Buenos Aires, Manantial.
TERÁN, OSCAR (2006): De utopías, catástrofes y esperanzas. Un camino Intelectual, Buenos Aires, Siglo XXI.

TERÁN, OSCAR (1991): Nuestros años sesentas. La formación de la nueva izquierda intelectual argentina 1955-1966, Buenos Aires, Puntosur. TERÁN, OSCAR (Carlos Ramírez) (1982): «Malvinas: la derrota, la locura y el mar», en: Le Monde Diplomatique. 